\title{
Investigation of Mechanical Properties of Low- Density Polyethylene with Copper Nanoparticles
}

\author{
M. V. Klychnikova ${ }^{1}$, Kyaw Ye $\mathrm{Ko}^{2}$, \\ ${ }^{1}$ Moscow Aviation Institute (National Research University), \\ Moscow, Volokolamskoe shosse, 4, 125993, \\ Russia \\ ${ }^{2}$ Defense Services Technological Academy (DSTA), \\ Mandalay-Lashio Highway Mandalay Division, Pyin Oo Lwin, \\ Myanmar
}

Received: March 16, 2021. Revised: August 19, 2021. Accepted: September 8, 2021. Published: September 10, 2021.

\begin{abstract}
In this work, it is shown that the method of the in situ preparation of Cu/LLDPE by combining the formation of a composite and a nanodispersed phase in the viscous-flow state of a polymer makes it possible to achieve a uniform distribution of nanoparticles in the matrix and effectively regulate their mechanical and functional properties.

The optimal concentration of $\mathrm{Cu}$ nanofiller was found to be $2-5 \%$, allowing to achieve the best mechanical properties. Comparative analysis of the physical and mechanical properties of Cu/LLDPE nanocomposites obtained by various methods shows that the deformation and strength characteristics of the 3CuLLDPE nanocomposite obtained by the in situ method are improved in comparison with the properties of the 3CuLLDPE nanocomposite, prepared by ex situ method.

The relationship between the filler content and the modulus of elasticity/tensile strength has been determined. With an increase in the filler content, the elastic modulus increases by $10-20 \%$, and the tensile strength decreases by $30 \%$. Elongation at break for samples with nanofiller content up to $3 \mathrm{wt}$. \% higher than unfilled polymer.
\end{abstract}

Keywords-Mechanical properties, composites, nanoparticles, polymers.

\section{INTRODUCTION}

$\mathrm{P}$ OLYMER materials are widely used for matrix insulation of metallic and semiconducting nanoparticles. The development of modern technology requires the creation of new structural materials with high elastic-strength characteristics, and, on their basis, structures with more effective weight data. The creation of polymer composites based on nano-modified binders has been one of the priority areas of research in the field of composite materials manufacturing technologies for many years [1]-[12]. In such nanocomposites, the polymer matrix promotes the stabilization and organization of metal-containing nanoparticles, and the dielectric medium can affect their optical and electronic properties. In turn, there are numerous examples indicating a change in the mechanical, thermal, and other properties of polymers in the presence of nanoparticles [13]-[29].

A new approach in nanotechnology proposes the use of fillers at the nanometer scale, since nanofillers have a large surface area, which makes them chemically very reactive and helps them bind better to the matrix. Nanoparticles embedded in a polymer matrix are attracting more and more interest due to the unique mechanical, optical, electrical and magnetic properties exhibited by nanocomposites and significantly improve them [13]-[16]. These improvements depend on the volumetric content of the filler as well as the type and characteristics of the nanofillers [17]-[33]. Nanofillers of a metallic or inorganic type can be considered an excellent candidate for hardening polymer matrices [34]-[58].

The development of modern technology requires the creation of new structural materials with high elastic-strength characteristics, and, on their basis, structures with more effective weight data. The creation of polymer composites based on nano-modified binders has been one of the priority areas of research in the field of composite materials manufacturing technologies for many years [1]-[12]. 
Significant progress has been made in this area [13]-[21]. The development of composite materials that improve their operational limits is based on the reinforcement of two or more fibers into a single polymer matrix, which leads to an improved material system called hybrid composites with a wide variety of material properties [22]-[25].

When creating nanocomposites, the key tasks are the development of efficient, reliable, and affordable production technologies for mass production, which make it possible to obtain materials with stable characteristics. The hand lay technique, also called wet lay, is the simplest and most widely used process for producing flat reinforced composites. The process consists of laying layers of a polymer in successive layering using an epoxy matrix. Wet-laying is a molding process that combines layers of reinforced carbon fiber with epoxy to create a high-quality laminate. Before starting the installation process, you must prepare the appropriate form. This preparation consists of cleaning the table and applying a release agent to the surface. The manual laying process can be divided into four main steps: mold preparation, epoxy coating, laying and curing. Form preparation is one of the most important steps in the installation process. This process requires dry reinforcement layers and the application of a wet epoxy matrix. They are connected together - reinforcing material, impregnated with a matrix - epoxy resin.

Adding metal nanoparticles to polymers is a way to obtain materials that combine the properties of polymers (lightness, formability, elasticity), on the one hand, and, on the other, the properties of metals (conductive, optical, magnetic, catalytic properties, etc.) and thus, in in particular, to develop new materials with functional properties for biomedicine applications, protective packaging for products or special equipment [30]-[38].

The aim of this work is to obtain composite materials based on linear low-density polyethylene (LLDPE) and copper nanoparticles and to establish the effect of synthesis conditions on the physical, mechanical and functional properties of the nanocomposite material [59]-[76]. To achieve this goal, the following tasks were solved: the development of a method for obtaining composite materials based on LLDPE and $\mathrm{Cu}$ nanoparticles and the study of the effect of nanofiller and its content, technological modes of production on the physical and mechanical properties of nanocomposite materials.

\section{OBTAINING POLYMER NANOCOMPOSITES}

In the case of $\mathrm{Cu} / \mathrm{LLDPE}$ nanocomposites obtained by the in situ method, metal nanoparticles are formed during the thermal decomposition of the precursor at the moment of its mixing with the polymer melt during extrusion. The process of obtaining a nanocomposite material is carried out under conditions of coincidence of the temperature ranges of the decomposition of metal precursor with the temperature range of the presence of polymers in a viscous-fluid state. The technical result is to simplify the production technology of film composite materials by combining the production of a composite material and a nanodispersed metal phase in one stage, as well as obtaining homogeneous (with uniformly distributed nanoparticles in a polymer matrix) film composite materials based on thermoplastic polymer matrices and copper nanoparticles with adjustable size and concentration of the dispersed phase.

The advantage of the proposed method is its technological simplicity, the availability of starting materials and thermoplastic polymers for large-scale production, the use of traditional technological cycles for processing polymeric materials (extrusion, mixing in micro-mixers, pressing) to obtain a film nanocomposite material.

Film samples of nanocomposite materials were obtained in two modes by casting using an injection molding machine (film thickness $1,85 \mathrm{~mm}$ ) or hot pressing (film thickness 0,21 $\mathrm{mm})$. The in situ approach was tested to obtain these nanocomposites. It was of interest to study how the technological conditions of the $\mathrm{Cu} / \mathrm{LLDPE}$ production process affect their elastic and deformation properties.

Table 1 shows the main physical and mechanical characteristics of $\mathrm{Cu} / \mathrm{LLDPE}$ nanocomposites obtained by the in situ method. The tensile curves of nanocomposite films are shown in Fig. 1.

Table I. Physical and mechanical properties of $\mathrm{Cu} / \mathrm{LLDPE}$ nanocomposites

\begin{tabular}{|c|c|c|c|}
\hline Sample & $\mathbf{E}, \mathbf{G P a}$ & $\sigma$ at rupture, $\mathrm{MPa}$ & $\varepsilon p, \%$ \\
\hline LLDPE & $0,27 \pm 0,01$ & $29,0 \pm 0,2$ & $1015 \pm 6$ \\
\hline 0,5Cu LLDPE & $0,29 \pm 0,01$ & $22,3 \pm 1$ & $1066 \pm 6$ \\
\hline 1Cu LLDPE & $0,32 \pm 0,01$ & $21,6 \pm 2,9$ & $1049 \pm 118$ \\
\hline 3Cu LLDPE & $0,30 \pm 0,02$ & $22,2 \pm 2,2$ & $1025 \pm 100$ \\
\hline 3,5Cu LLDPE & $0,29 \pm 0,01$ & $22,3 \pm 0,8$ & $1024 \pm 27$ \\
\hline 5Cu LLDPE & $0,33 \pm 0,01$ & $20,8 \pm 2$ & $1026 \pm 80$ \\
\hline 8Cu LLDPE & $0,31 \pm 0,01$ & $21,9 \pm 0,9$ & $992 \pm 40$ \\
\hline 20Cu LLDPE & $0,32 \pm 0,01$ & $19,5 \pm 2,1$ & $920 \pm 128$ \\
\hline
\end{tabular}

As evidenced by the obtained data, the general tendency of the influence of the content of nanofillers on the deformationstrength characteristics of materials is also preserved in the case of the studied $\mathrm{Cu} / \mathrm{LLDPE}$ nanocomposites.

\section{PHYSICAL AND MECHANICAL PROPERTIES OF POLYMER NANOCOMPOSITES}

Samples of the composite material were made on the basis of ED-20 epoxy resin with copper nanoparticles. The volumetric content of nanoparticles was up to $20 \%$, the diameter of the fibers was $50 \mathrm{~nm}$. Samples of three types were considered: 1) a quasi-homogeneous layered composite with a unidirectional reinforcement scheme, 2) a unidirectional composite with a wavelike layered structure, and 3) a pure matrix.

Mechanical tests were carried out on a universal electrical installation Instron $5969(50 \mathrm{kN})$ and Instron $5982(100 \mathrm{kN})$ 
(UK) with Bluehill 3 software. Compression tests were carried out. Test speed was $1 \mathrm{~mm} / \mathrm{min}$.

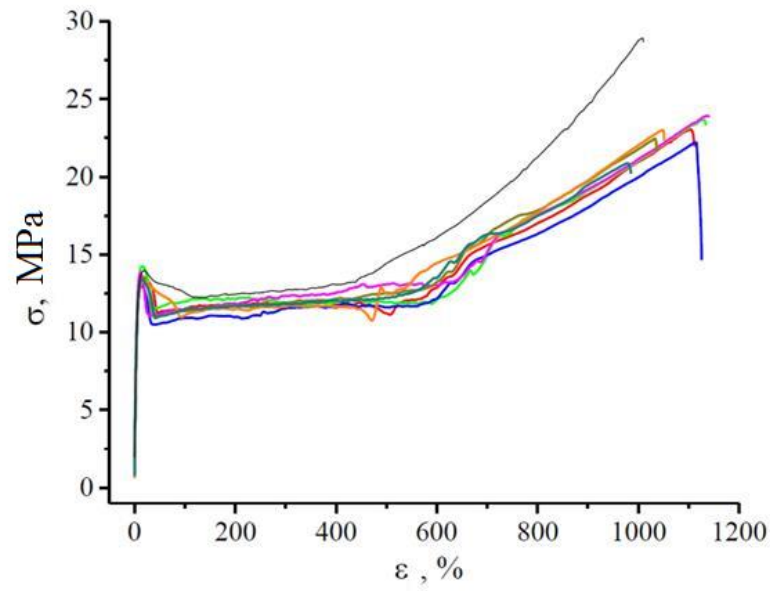

Fig. 1 Stress-Strain curves for initial LLDPE and $\mathrm{Cu} / \mathrm{LLDPE}$ nanocomposites with different filler contents

The graph shows that with an increase in the filler content, the elastic modulus increases, and the tensile strength decreases (Fig. 2). Note that the elongation at break for samples with a nanofiller content up to $3 \mathrm{wt} \%$ is higher than that for an unfilled polymer, and then with a further increase in the nanofiller concentration, the elastic properties of nanocomposites deteriorate (Fig. 3, 4).

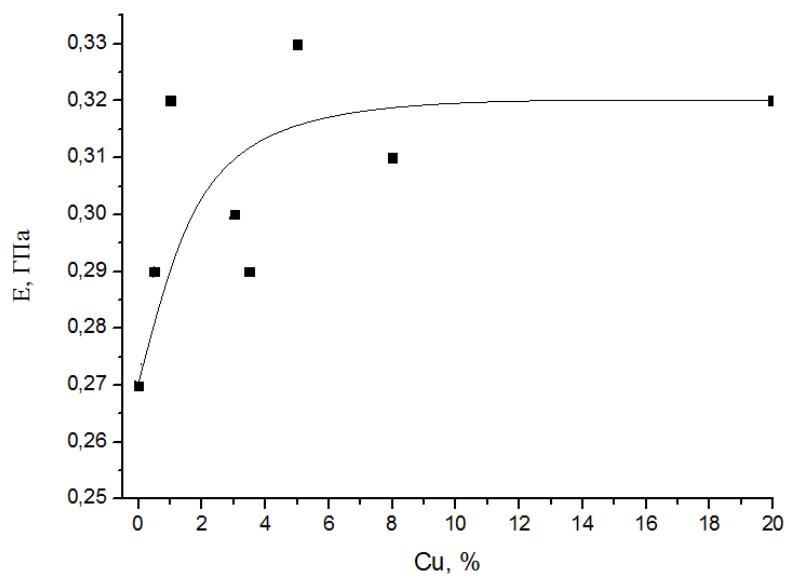

Fig. 2 Dependences of the elastic modulus of the $\mathrm{Cu} / \mathrm{LLDPE}$ nanocomposite on the filler content

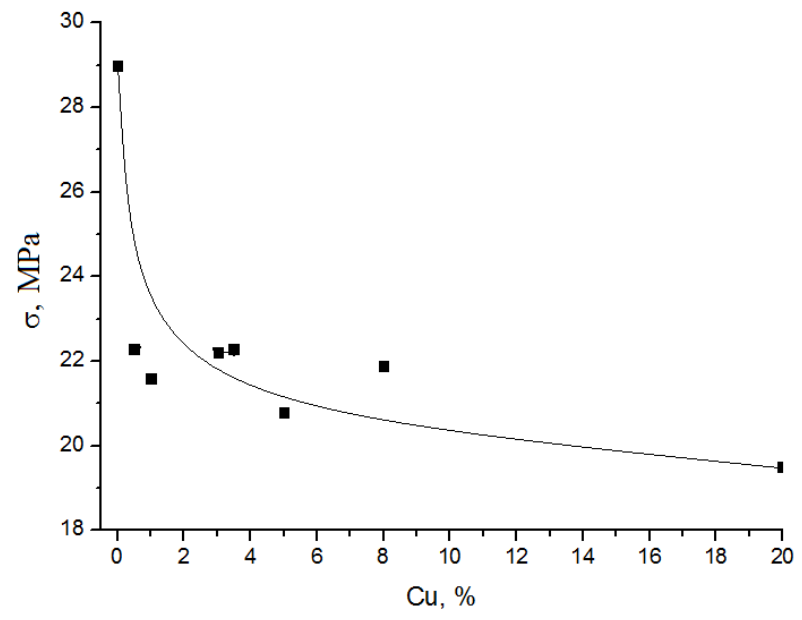

Fig. 3 Dependences of the tensile strength of the $\mathrm{Cu} / \mathrm{LLDPE}$ nanocomposite on the filler content

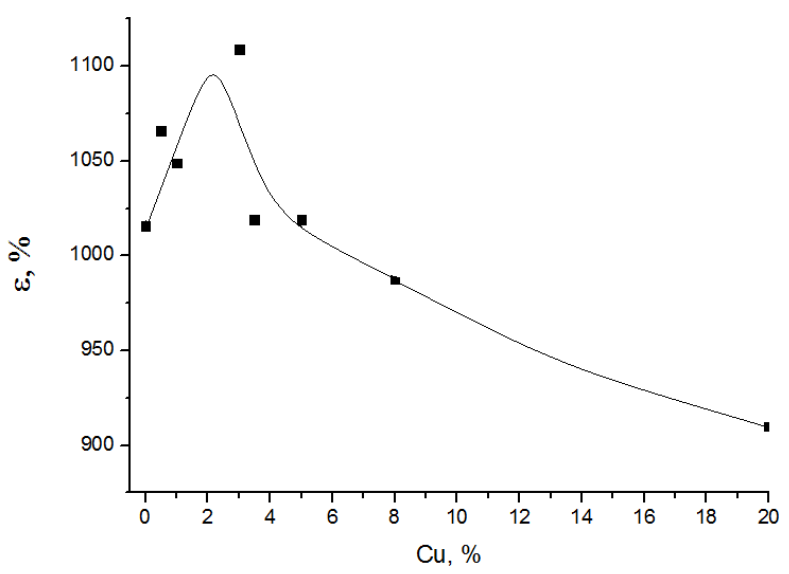

Fig. 4 dependence of elongation at break of $\mathrm{Cu} / \mathrm{LLDPE}$ samples on nanofiller content

Comparative analysis of the physical and mechanical properties of $\mathrm{Cu} / \mathrm{LLDPE}$ nanocomposites obtained by various methods shows that the deformation and strength characteristics of the 3CuLLDPE nanocomposite obtained by the in situ method are improved in comparison with the properties of the 3CuLLDPE nanocomposite, prepared by ex situ method. This opens new prospective for tailored fabrication of polymer composite materials for subsequent practical application as functional and construction materials.

\section{DISCUSSION AND THEORETICAL ISSUES}

To identify the elastic properties of a monolayer from the known values of the elastic moduli of composite samples with different reinforcement schemes, we will use the classical model of layered composites.

We use the model of spherical inclusions to model the properties of the filled matrix, assuming that the reinforcing particles of titanium dioxide are spheres. We assume that the particles are absolutely solid and do not collapse (the upper estimate). Bulk content $0,6 \%$. We use the Digimat - MF module, the averaging method of Mori - Tanaka. Strength criterion - according to the maximum principal stresses acting 
in the matrix.

If the initial volumetric content of inclusions is set to $3 \%$, the model predicts that the properties of the matrix will not change, since there are too few inclusions. The effect of the interfacial layer must be taken into account. For this, we will carry out a calculation with the setting of the effective volumetric content (volumetric content of the filler + volumetric content of the interfacial layer, under the assumption that their properties are equal). Let us select the effective volumetric content that allows us to describe the obtained experimental data in relation to the elastic modulus and ultimate strength.

The conducted studies allowed to investigate residual deformations in panels with an asymmetric reinforcement scheme based on the obtained analytical solution, as well as numerical modeling. Comparison of the results of analytical and numerical solutions with the obtained experimental data confirms the reliability and validity of the developed mathematical models and research methods for effective thermomechanical characteristics and residual stress-strain state of panels made of layered nanomodified materials.

An analytical calculation to determine the effective elastic properties of a monolayer will be carried out in the DigimatMF module using the Mori-Tanaka averaging method. Separately, we will also evaluate the effect of the filler on the elastic modulus of the matrix, considering the material containing only nanoparticles as inclusions. Based on these calculations, we will determine the "effective" volumetric content of inclusions, taking into account the influence of interphase layers formed around the inclusions. The influence of these layers, as will be shown below, cannot be neglected, since in this case underestimated values of the elastic characteristics of the matrix will be obtained. Therefore, in fact, knowing the modulus of elasticity of the nanomodified matrix from experiments, the content of the filler will be selected such that the calculation and experiment will coincide. The found value of the effective volumetric content of inclusions is further used in analytical and numerical calculations of the properties of a monolayer.

Numerical calculations will be carried out using the Digimat-FE module. The size of a cubic representative fragment was set by the system automatically. The effective elastic properties were calculated by determining the ratio of the volume-averaged representative fragment of the stress level to a given value of homogeneous deformations. In this case, the boundary conditions and the geometry of the fragment itself are periodic. The calculations were carried out using the finite element method.

Nanoparticles, even with a very low volumetric content (less than $1 \%$ ), are contained in such a fragment in a very large amount, and it is impossible to model their effect at this scale level. For example, a cubic fragment of a $1 \mu \mathrm{m}$ matrix contains more than thousand nanoparticles for a given volumetric content. Therefore, in particular, the nano-modified binder is white, while the usual binder is yellow. To model such materials, it is necessary to resort to multiscale approaches and to carry out a consistent determination of effective properties at various scale levels. This task is greatly simplified if the properties of the nanomodified matrix are known from experiments. In particular, it is known that its Young's modulus is $2.5 \mathrm{GPa}$. The missing characteristic is Poisson's ratio, which can be approximately taken unchanged, or estimated on the basis of analytical calculations using the found value of the "effective" volumetric content of the filler, which was done. Further, it suffices to numerically solve the averaging problem on a representative fragment containing only nanoparticles.

To obtain an analytical assessment of the properties of the nanomodified sample, the "effective" volumetric content of nanoparticles in the matrix was preliminarily determined, at which the calculated value of the effective Young's modulus of the nanomodified matrix coincides with the known experimental value $(2,5 \mathrm{GPa})$. It was found that if we do not take into account interfacial effects, then the calculation predicts the effective Young's modulus equal to 2,04 GPa, with an initial value of $2 \mathrm{GPa}$. That is, with such a low content $(1 \%)$ of even very hard inclusions, they should not have a significant effect on the properties of the material. The experimentally found increase in the matrix modulus can be explained by the influence of hardened and rigid interphase zones formed around the inclusions. For an approximate assessment of their influence, the concept of "effective" volumetric content of inclusions is introduced. It is assumed that the properties of the interphase zones and inclusions are the same, and the calculation should use the value of the "effective" volumetric content of inclusions, which is the sum of their real volumetric content and the content of interfacial zones. This value was approximately $10 \%$ for the considered composite. In this case, the predicted Young's modulus of the modified matrix is 2,5 $\mathrm{GPa}$, Poisson's ratio is 0,39 , and the thermal expansion coefficient is $5,76 \cdot 10^{-5}$.

Based on the results of experimental studies, the effective characteristics of a monolayer made of a composite material based on both conventional and nanomodified matrices were determined, and a solution to the corresponding inverse problem was obtained. It was found that the addition of nanoparticles within the experimentally found range of $2-5 \%$ leads to a slight increase in the longitudinal elastic modulus and shear modulus of the monolayer, as it can be seen from experimental data. In this case, there is an almost twofold decrease in the elastic modulus in the transverse direction and a decrease to zero Poisson's ratio. The reliability of the developed numerical models is confirmed by a good correlation between the results of both numerical and analytical solutions and the obtained experimental data on the study of the thermomechanical characteristics of nanomodified materials.

Currently, a large number of studies have been carried out to obtain and study the strength of composite materials. A large amount of experimental data dedicated to the synthesis 
and exploration of heterophase composites were obtained. However, well-known studies were carried out mainly for the case of quasi-static loading of materials. The effects of strain rate influence on the strength of composites with bent fibers have been studied to a much lesser extent, although they have also been considered. Analytical and numerical models are proposed to take into account the effects of curved stacking and the effect of fiber curvature. Some applied models, in particular, are used in standard software packages for finite element modeling. The buckling effects of fibers, even in the case of ideal straight-line packing, leads to a decrease in the compressive strength in relation to the ultimate tensile strength of the fiber composite by more than 1,5 times.

\section{CONCLUSION}

As a result of the studies carried out, it was shown that the in situ method of obtaining CuLLDLP nanocomposites makes it possible to obtain highly dispersed nanoparticles and achieve their more uniform distribution in the polymer matrix, which is reflected, as demonstrated, in improved deformation and strength characteristics of the materials obtained. The optimal concentration of $\mathrm{Cu}$ nanofiller was found to be $2-5 \%$, allowing to achieve the best mechanical properties. The relationship between the filler content and the modulus of elasticity/tensile strength has been determined. With an increase in the filler content, the elastic modulus increases by $10-20 \%$, and the tensile strength decreases by $30 \%$. Elongation at break for samples with nanofiller content up to $3 \mathrm{wt}$. \% higher than unfilled polymer.

\section{REFERENCES}

[1] A. V. Babaytsev, L. N. Rabinskiy, K. T. Aung, "Investigation of the contact zone of a cylindrical shell located between two parallel rigid plates with a gap," INCAS Bulletin, 12(Special Issue), pp. 43-52, 2020.

[2] V. G. Dmitriev, O. V. Egorova, E. I. Starovoitov, "Particularities of mathematical modeling of deformation processes for arched and panel designs of composites with large displacements and rotation angles," INCAS Bulletin, 12(Special Issue), pp. 53-66, 2020.

[3] O. V. Egorova, E. I. Starovoitov, "Non-stationary diffraction problem of a plane oblique pressure wave on the shell in the form of a hyperbolic cylinder taking into account the dissipation effect," INCAS Bulletin, 12(Special Issue), pp. 67-77, 2020.

[4] O. V. Tushavina, "Coupled heat transfer between a viscous shock gasdynamic layer and a transversely streamlined anisotropic half-space," INCAS Bulletin, 12 (Special Issue), pp. 211-220, 2020.

[5] M. Sha, Y. A. Utkin, O. V. Tushavina, P. F. Pronina, "Experimental studies of heat and mass transfer from tip models made of carbon-carbon composite material (cccm) under conditions of high-intensity thermal load," Periodico Tche Quimica, vol.17, i. 35, pp. 988-997, 2020.

[6] P. F. Pronina, O. V. Tushavina, E. I. Starovoitov, "Study of the radiation situation in moscow by investigating elastoplastic bodies in a neutron flux taking into account thermal effects," Periodico Tche Quimica, 17(35), pp. 753-764, 2020.

[7] L. N. Rabinskiy, S. A. Sitnikov, "Development of technologies for obtaining composite material based on silicone binder for its further use in space electric rocket engines," Periodico Tche Quimica, 15(Special Issue 1), pp. 390-395, 2018.

[8] N. A. Kucheva, V. Kohlert, "Mathematical modeling methods for estimation the thermophysical properties of heat-protective composite materials," Turkish Journal of Computer and Mathematics Education (TURCOMAT), vol. 12, no. 10, pp. 1606-1612, 2021.

[9] N. A. Kucheva, "Investigation of the mechanical properties of heat-protective highly porous composite materials using the effective medium model," Turkish Journal of Computer and Mathematics Education (TURCOMAT), vol. 12, no. 10, pp. 1613-1621, 2021.

[10]N. A. Kucheva, V. Kohlert, "Analytical solution of the problem of thermoelasticity for a plate heated by a source with a constant heat supply on one surface," Turkish Journal of Computer and Mathematics Education (TURCOMAT), vol. 12, no. 10, pp. 1622-1633, 2021.

[11] A. A. Orekhov, T. A. Utkin, P. F. Pronina, "Determination of deformation in mesh composite structure under the action of compressive loads," Periodico Tche Quimica, 17(35), pp. 599-608, 2020.

[12] S. Vakhneev, E. Starovoitov, "Damping of circular composite viscoelastic plate vibration under neutron irradiation," Journal of Applied Engineering Science, 18(4), pp. 699-704, 2020.

[13] V. A. Pogodin, L. N. Rabinskii, S. A. Sitnikov, "3D Printing of Components for the Gas-Discharge Chamber of Electric Rocket Engines," Russian Engineering Research, vol. 39, no. 9. pp. 797-799, 2019.

[14] O. A. Butusova, "Surface Modification of Titanium Dioxide Microparticles Under Ultrasonic Treatment," International Journal of Pharmaceutical Research, vol. 12, i. 4, pp. 2292-2296, 2020.

[15] O. A. Butusova, "Stabilization of Carbon Microparticles by High-Molecular Surfactants," International Journal of Pharmaceutical Research, vol. 12, Supplementary Issue 2, pp. 1147-1151, 2020.

[16] Yu. V. Ioni, A. Ethiraj, "New Tailor-Made Polymer Stabilizers for Aqueous Dispersions of Hydrophobic Carbon Nanoparticles," International Journal of Pharmaceutical Research, vol. 12, i. 4, pp. 3443-3446, 2020.

[17] G. A. Kalugina, A. V. Ryapukhin, "Impact of the 2020 Pandemic on Russian Aviation," Russian Engineering Research, vol. 41. no. 7, pp. 627-630, 2021.

[18]R. N. Zaripov, I. M. Murakaev, A. V. Ryapukhin, "Development of the Organization's Key Performance Indicators System in Order to Improve the Effectiveness of Its Human Capital and Risk Management," TEM Journal, vol. 10, no. 1, pp. 298-302, 2021.

[19]A. A. Kalugin, G. A. Kalugina, A. V. Ryapukhin, "Informational Support for the Sale of Passenger 
Aircraft," Russian Engineering Research, vol. 41, no. 2, pp. 183-187, 2021.

[20] R. N. Zaripov, I. M. Murakaev, S. V. Novikov, A. V. Ryapukhin, "Corporate Structure for Innovative Enterprises," Russian Engineering Research, vol. 40, no. 2, pp. 137-139, 2020.

[21]A. Y. Burova, "Concept of multistage discrete fourier transform without performing multiplications" Journal of Physics: Conference Series, vol. 1889, no. 2, 022003, 2021.

[22] A. Burova, "Reducing the Error of Digital Algorithms for Deductive Signal Processing Based on Their Multi-Stage Discrete Fourier Transform by the Difference Digital Filters," 22th International Conference on Digital Signal Processing and its Applications, DSPA 2020, no. 9213275, 2020.

[23] A. Y. Burova, "Minimization of asymmetry of thrust of dual-flow turbojet engines of airliner in accordance with the results of system analysis of thrust parameters," Asia Life Sciences, no. 2, pp. 629-643, 2019.

[24]N. V. Britvin, E. O. Karpukhin, "Determining the linear network code parameters to minimize the destructive factors influence in telecommunications systems and networks," Journal of Physics: Conference Series, vol. 1889, no. 3, 032016, 2021.

[25] S. V. Grazion, M. V. Mukomela, M. N. Erofeev, V. V. Spiryagin, S. S. Amelin, "Experimental Estimation of the Waveguide Effect on the Acoustic Emission Signal Parameters in Monitoring Facilities with a Long Surface Radius of Curvature," Journal of Machinery Manufacture and Reliability, vol. 49, no. 11, pp. 971-979, 2020.

[26] M. I. Gordeeva, "Methods for forecasting and control of the phase composition and residual voltage in $\mathrm{Al}-\mathrm{Cu}-\mathrm{Li}$ alloys in friction mixing welding" Journal of Physics: Conference Series, vol. 1713, no. 1, 012017, 2020.

[27] Yu. V. Ioni, "Nanoparticles of noble metals on the surface of graphene flakes," Periodico Tche Quimica, vol. 17, no. 36, pp. 1199-1211, 2020.

[28] O. A. Butusova, "Vinyl Ether Copolymers as Stabilizers of Carbon Black Suspensions," International Journal of Pharmaceutical Research, vol. 12, Supplementary Issue 2, pp. 1152-1155, 2020.

[29] M. O. Kaptakov, "Catalytic Desulfuration of Oil Products under Ultrasonic Treatment," International Journal of Pharmaceutical Research, vol. 12, Supplementary Issue 2, pp. 1838-1843, 2020.

[30]B. A. Garibyan, "Enhancement of Mechanical Properties of Inorganic Glass under Ultrasonic Treatment," International Journal of Pharmaceutical Research, vol. 12, Supplementary Issue 2, pp. 1829-1832, 2020.

[31]M. O. Kaptakov, "Enhancement of Quality of Oil Products under Ultrasonic Treatment," International Journal of Pharmaceutical Research, vol. 12, Supplementary Issue 2, pp. 1851-1855, 2020.

[32]O. A. Butusova, "Adsorption Behaviour of Ethylhydroxyethyl Cellulose on the Surface of Microparticles of Titanium and Ferrous Oxides,"
International Journal of Pharmaceutical Research, vol. 12, Supplementary Issue 2, pp. 1156-1159, 2020.

[33]A. N. Tarasova, "Vibration-based Method for Mechanochemical Coating Metallic Surfaces," International Journal of Pharmaceutical Research, vol. 12, Supplementary Issue 2, pp. 1160-1168, 2020.

[34]B. A. Garibyan, "Mechanical Properties of Electroconductive Ceramics," International Journal of Pharmaceutical Research, vol. 12, Supplementary Issue 2, pp. 1825-1828, 2020.

[35]M. O. Kaptakov, "Effect of Ultrasonic Treatment on Stability of $\mathrm{TiO}_{2}$ Aqueous Dispersions in Presence of Water-Soluble Polymers," International Journal of Pharmaceutical Research, vol. 12, Supplementary Issue 2, pp. 1821-1824, 2020.

[36] Yu. V. Ioni, "Synthesis of Metal Oxide Nanoparticles and Formation of Nanostructured Layers on Surfaces under Ultrasonic Vibrations," International Journal of Pharmaceutical Research, vol. 12, i. 4, pp. 3432-3435, 2020.

[37]A. N. Tarasova, "Effect of Reagent Concentrations on Equilibria in Water-Soluble Complexes," International Journal of Pharmaceutical Research, vol. 12, Supplementary Issue 2, pp. 1169-1172, 2020.

[38]A. N. Tarasova, "Effect of Vibration on Physical Properties of Polymeric Latexes," International Journal of Pharmaceutical Research, vol. 12, Supplementary Issue 2, pp. 1173-1180, 2020.

[39] O. A. Butusova, "Design and Properties of Magnetically Controlled Sorbents," Turkish Journal of Computer and Mathematics Education (TURCOMAT), vol. 12, no. 5, pp. 515-519, 2021.

[40] O. A. Butusova, "Application of Magnetically Controlled Sorbents for Detoxication," Turkish Journal of Computer and Mathematics Education (TURCOMAT), vol. 12, no. 5, pp. 520-524, 2021.

[41] Yu. V. Ioni, A. Ethiraj, "Study of Microparticles Surface Modification by Electrokinetic Potential Measuring," International Journal of Pharmaceutical Research, vol. 12, i. 4, pp. 3436-3439, 2020.

[42] S. A. Kolesnik, N. A. Bulychev, "Numerical analytic method for solving the inverse coefficient problem of heat conduction in anisotropic half-space," Journal of Physics: Conference Series, 1474(1), 012024, 2020.

[43]N. A. Bulychev, E. L. Kuznetsova, "Ultrasonic Application of Nanostructured Coatings on Metals," Russian Engineering Research, 39 (9), pp. 809-812, 2019.

[44] N. A. Bulychev, V. V. Bodryshev, L. N. Rabinskiy, "Analysis of geometric characteristics of two-phase polymer-solvent systems during the separation of solutions according to the intensity of the image of micrographs," Periodico Tche Quimica, 16(32), pp. 551559, 2019.

[45]A. V. Perchenok, E. V. Suvorova, A. A. Farmakovskaya, V. Kohlert, "Application of vinyl ether copolymers for surface modification of carbon black," International Journal of Circuits, Systems and Signal Processing, vol. 15, pp. 1300-1304, 2021. 
[46] A. V. Perchenok, E. V. Suvorova, A. A. Farmakovskaya, V. Kohlert, "Stabilization of aqueous dispersions of inorganic microparticles under mechanical activation," WSEAS Transactions on Applied and Theoretical Mechanics, vol. 16, pp. 127-133, 2021.

[47] N. A. Bulychev, A. V. Ivanov, "Effect of vibration on structure and properties of polymeric membranes," International Journal of Nanotechnology, vol. 16, nos. 6/7/8/9/10, pp. $334-343,2019$.

[48] N. A. Bulychev, A. V. Ivanov, "Nanostructure of OrganicInorganic Composite Materials Based on Polymer Hydrogels," International Journal of Nanotechnology, vol. 16, nos. 6/7/8/9/10, pp. 344 - 355, 2019.

[49] N. A. Bulychev, A. V. Ivanov, "Study of Nanostructure of Polymer Adsorption Layers on the Particles Surface of Titanium Dioxide," International Journal of Nanotechnology, vol. 16, nos. 6/7/8/9/10, pp. $356-365$, 2019.

[50]N. A. Bulychev, L. N. Rabinskiy, O. V. Tushavina, "Effect of intense mechanical vibration of ultrasonic frequency on thermal unstable low-temperature plasma," Nanoscience and Technology: An International Journal, 11 (1), pp. 15-21, 2020.

[51]N. A. Bulychev, L. N. Rabinskiy, "Ceramic Nanostructures Obtained by Acoustoplasma Technique," Nanoscience and Technology: An International Journal, 10 (3), pp. 279-286, 2019.

[52] Yu. V. Ioni, "Effect of Ultrasonic Treatment on Properties of Aqueous Dispersions of Inorganic and Organic Particles in Presence of Water-Soluble Polymers," International Journal of Pharmaceutical Research, vol. 12, i. 4, pp. 3440-3442, 2020.

[53] O. A. Pashkov, "Influence of Polymer Coatings on the Mechanical Properties of Steel Samples in Tensile and Bending Tests," Turkish Journal of Computer and Mathematics Education (TURCOMAT), vol. 12, no. 5, pp. 542-548, 2021.

[54] O. A. Pashkov, "Investigation of the Effect of Steel Plate Size and Elevated Temperature on Critical Load in Stability Tests," Turkish Journal of Computer and Mathematics Education (TURCOMAT), vol. 12, no. 10, pp. 1657-1663, 2021.

[55] Y. Sun, O. V. Egorova, E. L. Kuznetsova, "Identification of the front angle of a plane acoustic oblique pressure wave on convex surfaces with the use of analytical solution," Journal of the Balkan Tribological Association, 27(2), pp. 189-197, 2021.

[56] O. A. Pashkov, "Theoretical calculation of the thickness of interphase zones in the Al-Al2O3 composite," Turkish Journal of Computer and Mathematics Education (TURCOMAT), vol. 12, no. 10, pp. 1672-1677, 2021.

[57] O. A. Pashkov, "Experimental and Theoretical Study of Mechanical Properties of Matrix Composite Materials," Turkish Journal of Computer and Mathematics Education (TURCOMAT), vol. 12, no. 10, pp. 1678-1684, 2021.

[58] I. P. Lifanov, A. N. Astapov, V. S. Terentieva, "Deposition of heat-resistant coatings based on the $\mathrm{ZrSi} 2-$ MoSi2-ZrB2 system for protection of non-metallic composite materials in high-speed high-enthalpy gas flows," Journal of Physics: Conference Series, vol. 1713, no. 1, pp. 012025, 2020.

[59] I. P. Lifanov, A. A. Yurishcheva, A. N. Astapov, "Hightemperature protective coatings on carbon composites," Russian Engineering Research, vol. 39, no. 9, pp. $804-$ 808, 2019.

[60] A. N. Astapov, I. P. Lifanov, M. V. Prokofiev, "Hightemperature interaction in the $\mathrm{ZrSi} 2-\mathrm{ZrSiO} 4$ system and its mechanism," Russian Metallurgy (Metally), no. 6, pp. $640-646,2019$.

[61] A. N. Astapov, E. L. Kuznetsova, L. N. Rabinskiy, "Operating capacity of anti-oxidizing coating in hypersonic flows of air plasma," Surface Review and Letters, 26(2), pp. 1850145, 2019.

[62] L. N. Rabinskiy, O. V. Tushavina, E. I. Starovoitov, "Study of thermal effects of electromagnetic radiation on the environment from space rocket activity," INCAS Bulletin, 12 (Special Issue), pp. 141-148, 2020.

[63] A. V. Babaytsev, A. A. Orekhov, L. N. Rabinskiy, "Properties and microstructure of AlSi10Mg samples obtained by selective laser melting," Nanoscience and Technology: An International Journal, 11(3), pp. 213222, 2020.

[64] O. V. Egorova, Y. K. Kyaw, "Solution of inverse nonstationary boundary value problems of diffraction of plane pressure wave on convex surfaces based on analytical solution," Journal of Applied Engineering Science, 18(4), pp. 676-680, 2020.

[65]M. O. Kaptakov, "Effect of Thin Polymer Layers on Mechanical Properties of Metal Surfaces," Turkish Journal of Computer and Mathematics Education (TURCOMAT), vol. 12, no. 5, pp. 525-529, 2021.

[66] B. A. Garibyan, "Determination of the Elastic Modulus of the Coating Using a Spherical Indenter," Turkish Journal of Computer and Mathematics Education (TURCOMAT), vol. 12, no. 10, pp. 1594-1600, 2021.

[67] M. O. Kaptakov, "Modelling of Mechanical Properties of Metal Plates with Polymer Coatings," Turkish Journal of Computer and Mathematics Education (TURCOMAT), vol. 12, no. 5, pp. 530-534, 2021.

[68] V. F. Formalev, S. A. Kolesnik, E. L. Kuznetsova, "Analytical study on heat transfer in anisotropic space with thermal conductivity tensor components depending on temperature," Periodico Tche Quimica, 15(Special Issue 1), pp. 426-432, 2018.

[69] V. F. Formalev, S. A. Kolesnik, E. L. Kuznetsova, "Analytical solution-based study of the nonstationary thermal state of anisotropic composite materials," Composites: Mechanics, Computations, Applications, 9(3), pp. 223-237, 2018.

[70] V. F. Formalev, S. A. Kolesnik, E. L. Kuznetsova, L. N. Rabinskiy, "Origination and propagation of temperature solitons with wave heat transfer in the bounded area during additive technological processes," Periodico Tche Quimica, 16(33), pp. 505-515, 2019.

[71]B. A. Garibyan, "Theoretical Estimations of Influence of Polymer Coatings on the Elastic Modulus and Ultimate 
Strength of Steel Samples," Turkish Journal of Computer and Mathematics Education (TURCOMAT), vol. 12, no. 10, pp. 1651-1656, 2021.

[72] M. O. Kaptakov, "Investigation of Effective Mechanical Characteristics of Nanomodified Carbon-Epoxide Composite by Numerical and Analytical Methods," Turkish Journal of Computer and Mathematics Education (TURCOMAT), vol. 12, no. 5, pp. 535-541, 2021.

[73]M. O. Kaptakov, "Obtaining of Carbon Fibers Based Composite Materials and Study of Their Mechanical Properties," Turkish Journal of Computer and Mathematics Education (TURCOMAT), vol. 12, no. 10, pp. 1601-1605, 2021.

[74] V. F. Formalev, S. A. Kolesnik, E. L. Kuznetsova, "Mathematical modeling of a new method of thermal protection based on the injection of special coolants," Periodico Tche Quimica, 16(32), pp. 598-607, 2019.

[75] V. F. Formalev, S. A. Kolesnik, E. L. Kuznetsova, "Identification of new law for decomposition of bonding heat-shielding composite materials," Asia Life Sciences, (1), pp. 139-148, 2019.

[76] E. L. Kuznetsova, A.V. Makarenko, "Mathematical model of energy efficiency of mechatronic modules and power sources for prospective mobile objects," Periodico Tche Quimica, 16 (32), pp. 529-541, 2019.

\section{Creative Commons Attribution License 4.0} (Attribution 4.0 International, CC BY 4.0)

This article is published under the terms of the Creative Commons Attribution License 4.0

https://creativecommons.org/licenses/by/4.0/deed.en_US 